\title{
What's Queer about Remy, Ratatouille, and French Cuisine?
}

\author{
Laure Murat
}

"What's queer about Remy?" is the question that I will ask about Ratatouille (2007), the spectacular animated blockbuster film from Pixar Studios that won an Academy Award for Best Animated Feature and a dozen other international prizes. What visual and textual rhetoric does the film use to transform a rat, an object of disgust associated with disease and filth, into a celebrated French chef? I propose to analyze the ways in which Ratatouille queers not just sexualized categories but also the spatialization of social roles, the notion of national culture, as well as the opposition between humans and non-humans.

Ratatouille begins when a hundred rats flee a suburban house and move to Paris via the sewage system. Remy, the hero, is separated from his family and saved by a book that he uses as a raft. The book/raft, Anyone Can Cook, was written by his idol, the famous French chef Auguste Gusteau, who recently passed away. Helped by Gusteau's ghost, a Tinker Bell-like hologram that regularly pops up at critical junctures, Remy ends up in the kitchen of "Gusteau's," the most famous Parisian restaurant now run by the cantankerous Skinner. Befriended by Linguini, a young garbage boy who knows nothing about cooking, he devises a clever stratagem: Hidden under 
the chef's hat, he will direct Linguini's moves by pulling his hair as a puppet master would pull strings; Remy cooks through Linguini who becomes increasingly successful.

When Linguini, who turns out to be Gusteau's biological son, claims his inheritance, Skinner swears to avenge himself. Having discovered Remy's role, he kidnaps him just before a visit of the formidable food critic Anton Ego who had already criticized Gusteau's cuisine. When Remy escapes in the nick of time, Linguini reveals the truth to his co-workers: a rat is the real chef. They leave the restaurant horrified. Rejected by humans, Remy calls the rats to the rescue and cooks his "chef d'œuvre": a "ratatouille" that Anton Ego finds sublime. Gusteau's, however, must close down after a visit by the food hygiene inspectors who find rats in the kitchen. At the end of the film, Linguini and Remy have opened a new restaurant, La Ratatouille, where humans and rats cohabitate peacefully.

\section{Queerness as the Blurring of Boundaries: A Human-Non-Human Closet Space}

At the beginning of the film, Remy points out what is at stake in Ratatouille: "What's my problem? First, I am a rat. Second, I have an exceptional sense of taste and smell." Remy's problem is that the combination is queered by his determination to use his gift in a way that excludes himself from his community of fellow rats. His sense of smell could make him a useful "poison sniffer" among rats but he wants to be a chef. On the other hand, as a rat he is not welcome in human kitchens and positions himself outside two communities even though he belongs to both. Because Remy does not wish to belong to his kind, he occupies a queer space of exclusion: $\mathrm{He}$ is too sophisticated for rats and still a rat to humans. His only solution is to occupy a closet that the film constructs as the inside of the "chef's hat" from which Remy can queer his own identity as well as the assumptions on which the human/non-human opposition are founded.

Remy is not visually different from other rats. Much thinner and shorter than his fat brown brother Emile, smaller and weaker than his father Django, he is drawn with a substantially bigger and "super sensitive" pink nose. He does not identify with his rat's life: He denies being a garbage thief, and refuses to get his paws dirty because he is only interested in gastronomy. He does not want to scavenge for food, but wishes to "create" by exploring the most subtle combinations of ingredients and flavors. $\mathrm{He}$ leads, as he puts it, "a secret life," and has even learned how to read, which Emile finds outrageously subversive: "God! Does Dad know?” he exclaims 
when he finds out. His characterological traits, physical appearance, and preferences thus construct him as an outsider of sorts.

Remy's secret life does not fit within the spatial borders constructed within the film either. In Ratatouille, the world of the rats lies below, in the darkness and humidity, the sewer, the streets, and the garbage. Humans live above them, in the "city of lights" and refined food. The camera constantly pans up and down, to indicate the point of view of rats and humans. This vertical inter-species hierarchy corresponds to a horizontal division between the world of the kitchen, a mysterious laboratory where everybody shouts, and the dining room where guests talk softly while listening to classical music. Hidden under Linguini's hat, Remy occupies the apex of this spatial configuration. He can see everything and everyone in the kitchen because the chef's hat is transparent but he cannot be seen by anyone else- except by the spectator, who is aware of the existence of this queer space. The spatial coordinates are thus bifurcated. A vertical hierarchy corresponds to the horizontal one, but Remy's position is neither within one or other of the four spaces produced. Instead, he is privy to all four hierarchical spaces, moving in and out of them both physically and through the exercise of his sight through the transparent (to him and the spectators) chef's hat. The spatial transgression of hierarchies and the visual omniscience of Remy's position confounds binary constructions while acknowledging their power.

According to Brad Bird, the director of the movie, the trick of the hat's semi-transparency emerged during the making of the film and was his "most important idea," a "very liberating one." Correspondingly, Remy did not need to peek out of the hat in order to see what was going on and thus risk being discovered. These ingenious "refracted transparencies" where Remy can look out without being seen while we, the viewers can see through the hat, suggests new perspectives on the closet.

The closet has been a classic topos among queer theorists as Katherine Bourguignon reminds us:

The closet stands as a metaphor for the silence of secrets, the upkeep of the status quo, and the distinction between private and public, inside and outside. Eve Kosofsky Sedgwick labeled the closet "a shaping presence" in the lives of gay people, and John Clum noted that "the closet is less a place than a performance-or series of performances, maintained by the heterosexist wish for, and sometimes enforcement of, homosexual silence and invisibility." (Bourguignon 4) 
In Ratatouille, the chef's hat is clearly this "shaping presence" and a protected "series of performances" in Remy's life. Its transparency associates it to Sedgwick's "glass closet" ( ( 64-65). In Epistemology of the Closet, she describes it as an open secret, a place where gay people live as if nobody knew they were gay, although everybody knows. Ratatouille queers the open secret because the "glass closet" is both translucent and opaque, reflecting and refracting multiple visibilities for differentially located viewers. Remy, from within the hat, knows who the real cook is and observes the scene, while the official cooks looking at him do not see him. The audience, however, can see him and knows about the closet while the cooks see their own image reflected in the white chef's hat. Bird has constructed a refracting closet that both includes (the subjectivity of the hero and the spectator) and excludes (the characters).

In addition to the queering of Remy's character and of space and visuality, effects of queer inclusion and exclusion are produced by the film's use of languages. When rats talk to each other, the spectator is included: The rats speak English. But if one of the characters in the story hears their conversation, the spectator only perceives incomprehensible gurgling sounds and is thus re-aligned with humans. The film lets the audience move in and out of an inter-species third space that constructs an intimate and rather queer relationship between (some) rats and (some) humans.

The spectator is thus invited to be part of Remy's experiment. As the hidden cook who transforms a boy into a puppet, he brings together animals, humans, and non-humans as well as ingredients. This position, however, is never celebrated as a hybrid paradise and the existence of a queer audience is both presented as a possibility and questioned: It is perhaps as spectral as Gusteau's ghost to whom Remy talks when he complains about the difficulty of his position: "I am sick of pretending. I pretend to be a rat for my father; I pretend to be a human through Linguini. I pretend you exist so I have someone to talk to!"

On the one hand, Ratatouille is the story of a successful coming-out, which helps Remy gain the esteem of his father, of Anton Ego, and the team of cooks who agree to work with him, while queering the original division of space. At the end of the film, the recognition of Remy as a real chef brings about the ruin of the old system of domination. In terms of space and species, the rodents, now accepted by the kitchen team, have turned the attic of the restaurant into their own nicely decorated dining room lit up with candles. Downstairs, spaces and roles are redistributed: The kitchen now opens onto a cozy Parisian bistro quite unlike the old- 
fashioned and rather pretentious Gusteau's. In terms of social power, the fierce and almighty Anton Ego, now a discredited critic, is hardly recognizable: He is a smiling and relaxed customer, whom Remy greets from the kitchen, wearing his own chef's hat.

\section{Queering Sexuality and/or Gender Roles?}

Remy is also queer to the extent that he troubles the heteronormativity symbolized by his father and brother. Their male bonding and straight complicity are especially evident when they mock Remy's slight frame, sniggering: "Is it a shortage of food or an excess of snobbery?" Remy's difference is not described as a form of gayness; his queerness is an "otherness" that goes beyond gender or (a)sexuality, though the slightness of his frame suggests a stereotypical image of the gay male in the eyes of heteronormative masculinity. He is also a cook who mingles with human beings. Remy's presence in the kitchen leads to a queering of essentialist norms. His metaphorical description of his journey, however, is lost on his father who insists on borders between species:

Remy: Every bird has to leave the nest...

Django: We are not birds, we are rats! We don't leave the nest, we make it bigger!

Remy: Perhaps I am a different kind of rat!

Django: Maybe you are not a rat at all!

Remy: Perhaps it's a good thing!

Django explains: "You are talking like a human!" his comment taking the discussion toward considerations of "nature." To convince his son that he is heading for disaster if he associates with humans, the father leads him to the shop window of a rat exterminator where dozens of rat corpses hang from traps:

Django: This is the way things are. You can't change nature.

Remy: Change is nature, Dad. The part that we can influence. And it starts when we decide. (Remy walks away.)

Django: Where are you going?

Remy: With luck, forward.

Ratatouille seems to be an anti-essentialist manifesto that suggests a move forward through escaping the closet/prison of "rathood." He refutes not only "family values" but also clichés about genealogy, heredity, and bloodlines. Remy's exceptional gift for cooking is thus mirrored by Linguini's 
lack of inherited talent. At the same time, given the way he moves both back-and-forth and sideways between different spaces, Remy also draws the complex lines of a queer trajectory that is not just about "coming out" but constantly moving in and out, forward as well as sideways.

Even Anton Ego, at the end of the film, suggests that he is willing to privilege art and downplay the significance of origin and identity:

I have made no secret of my disdain for Chef Gusteau's famous motto: "Anyone can cook." But I realize that only now do I truly understand what he meant. Not everyone can become a great artist, but a great artist can come from anywhere. It is difficult to imagine more humble origins than those of the genius [Remy] now cooking at Gusteau's. He is, in this critic's opinion, nothing less than the finest chef in France.

It is worth noting, however, that the film's quasi-theoretical affirmation of queer perspectives does not necessarily promote an unambiguously progressive gender agenda. The portrayal of women in Ratatouille deserves a few remarks. Of the four female characters, two make only fleeting appearances. Food critic Solène LeClair barely says a word during her threeminute on-screen performance and Anton Ego's mother is seen only in his blissful dream as the holy figure who cooked the perfect ratatouille of his childhood. The others are two different types of viragos who respectively embody past and modern France. Mabel, the old lady who evicts the rats from her suburban home, will probably be perceived as a fearsome villain by the children who constitute the film's target audience (she shoots her rifles in a rather terrifying way). The only well-rounded female character is also the only woman in the kitchen. Colette is a caricature of the feminist virago, a shorthaired brunette who speaks English with a strong French accent and rides a black motorcycle. ${ }^{2}$ Her butch persona may be the only factor that queers the representation of Remy's stereotypically gendered professional world. If cooking, like hairdressing or sewing, is seen as a traditionally feminine activity, when practiced at a high professional level, it becomes a male-dominated vocation (and is then called haute coiffure, haute couture, and gastronomy). Unlike men involved in hairdressing or haute couture, however, the chef is not a typically gay icon. The world of professional cooking remains a very straight, heterosexist, if not macho bastion. In that sense, Colette, despite her prominent role as a cook, remains under Skinner's command and in the shadow of Gusteau's memory. She was trained a dutiful soldier. She religiously follows the Master's recipes, unable to depart from his book or to let others try. She is thus condemned to (mechanical) reproduction, an activity usually associated with women. 


\section{Queering the Race, the Nation, and Its Cuisine}

If traditional gender roles remain relatively undisturbed in Ratatouille, then the way in which the film queers notions of ethnicity and national identities is deserving of further consideration. Ratatouille is an American film about French cuisine and Frenchness that queers both American and European stereotypes about identities and national cultures.

Ratatouille can hardly be read as a typically American celebration of individualist triumph. The film does not replace one authoritarian and solitary chef (Skinner) with a better individual. Instead, it celebrates solidarity (among rats and humans). The team of cooks wins over Anton Ego's heart. Moreover, the relationship between cuisine as art and imagination, and cuisine as commerce is systematically addressed: Skinner's ambition to make a fortune by creating a frozen food empire using Gusteau's name is obviously criticized. The mixing between members of different communities or species is presented as the antidote to a compartmentalized and sanitized world: The neutralization of the hygiene inspector who is locked in the cellar by rats is presented as a moment of triumph.

Ratatouille is therefore a good example of what Judith Halberstam has recently called "Pixarvolt," the technological and ideological revolution promoted by Pixar Studios in films such as Toy Story (I995), Chicken Run (2000), Finding Nemo (2003), and Robots (2005). The films rethink "class struggle, communitarian revolt and queer embodiments . . . [as well as] social relations." Halberstam points out that "[i]n many of those "queer fairytales' romance gives way to friendship, individuation gives way to collectivity and 'successful' heterosexual coupling is upended, displaced and challenged by queer contact." 3 In Ratatouille, the romance between Linguini and Colette appears anecdotal compared to the relationship between Linguini and Remy. Cooking, an activity usually associated with the most traditional aspects of French culture becomes a metaphor of queering because the rat-cook promotes mixing and mixture in and out of the kitchen.

The kitchen team is a melting pot of marginal individuals of different nationalities and ethnicities. The relation between the ideology of the "melting pot" and French universalism and cuisine, however, is a complex one. Horst, a German ex-convict, claims to have robbed the second largest bank in France, created a hole in the ozone layer over Avignon, and murdered a man with his thumb. Larousse, named after the famous dictionary, smuggled arms for the Resistance but nobody knows precisely which 
Resistance. Lalo, who could be Caribbean, left his home at age twelve to become a circus acrobat. Pompidou, whose name comically references a former president of the Fifth Republic, is a compulsive gambler who was banned from casinos in Las Vegas and Monaco. The opportunistic Skinner, whose gesticulations and funny faces have been modeled on Louis de Funès, looks North African. Linguini is a an illegitimate Franco-Italian boy and he cannot be separated from the invisible "little chef." The kitchen team is a queer type of community. All the members of this diverse community of border-crossers and marginals share a passion for French cuisine; furthermore, their professional activity is also associated with subversion and marginality: "We are artists, pirates. We are more than cooks," says Colette.

But what kind of "pirates" are the cooks and what type of subversion are we talking about here? Is the queering of the team and its preference for mixing politically queer? Is not French cuisine the culinary equivalent of French universalism, which stipulates that anyone can become French as long as one adopts French culture? Is the book Anyone Can Cook a recipe for a more traditional form of integration?

A look at the emblematic dish chosen to represent Remy's triumph reveals that his "ratatouille" is also the site of ambiguities and contradictory signals regarding the nation and its communities. The ratatouille of the film is more than a typical French recipe such as Veau Marengo that might connote French gastronomy on the international scene. Ratatouille was obviously chosen because it includes the word "rat," but it also serves a more symbolic purpose. The Introduction to Dakin's book Ratatouille: The Guide to Remy's World suggests that the ratatouille is capable of queering the opposition between the "high" and "low" kitchen:

There's a dish in France that's so popular it's eaten in thousands of homes every day. Its name? Well, that's the funny part, it doesn't have a posh name that will make you stop and wonder about what you're really eating ... It's a kind of vegetable stew that even looks a bit ordinarylike leftovers. But sometimes great things don't come with a fancy name, or a special reputation. Sometimes they don't even look that great. But despite all that, when you really get to know them, they can be kind of special. Kind of like a rat named Remy ... (7)

The emphasis on simplicity, leftovers, and the refusal to define "great things" as what is "posh" and "fancy" is also present in Trésor de la langue française, which, under "ratatouille," proposes: 
A- Dish made of various ingredients cut in pieces and cooked together.

B- I/Dated. Stew (bad) . . roughly cooked. 2/ Fig. : heterogeneous mixing. Synon. Salad, hodgepodge. Life is made of a damned ratatouille of ingredients. (Arnoux, Rhône, 203). Etymologically, the word would come from a crossing between "tatouiller" which means "to stir, to handle a lot; to spill in the mud" and "ratouiller," "to make murky, to shake, to stir; to make dirty."4

The definition suggests that the distance between "mud," "filth," and ratatouille is no greater than between the garbage boy and his chef d'oeuvre. The film suggests that the culinary work of art implies the transformation of what the norm treats as discarded material. The "ratatouille" is associated with mixing and murkiness, and it is no coincidence that it is cooked by the "rejects" of society (a rat, an illegitimate son, a group of marginals).

From within France, however, ratatouille was not recognized as typically or authentically French (regardless of whether Frenchness here is queer or not). François Simon, the food critic of Le Figaro who is thought to have inspired the character of Anton $\mathrm{Ego}^{5}$ saw the "ratatouille" of the film as

a miserable rosette of eggplant, zucchinis and tomatoes (in the posh style of American new cuisine of I997-I998), far from this delightfully stewed and luscious ratatouille we know. We then think, rather unabashedly, that any rat could become a movie director. (Simon, "Drôlement")

The critic has a point even if we disagree with the implications of his "we" ("we," the French). After all, what the movie crew calls a ratatouille is a "confit Bayaldi," invented by French chef Michel Guérard in 1976, and reinterpreted by Thomas Keller, the American chef of the French Laundry (California) and main consultant for the animated movie. This American smoothed-out version of ratatouille does not emphasize the "murky" aspects of the dish and presents us with a very clean version of what is supposed to be a popular stew and a figurative "melting pot."

On the other hand, if the Americanized version of the French ratatouille is not as queer as its supposedly more authentic original, the representation of how cuisine relates to communities constitutes an ambiguous homage to contemporary France: It is constructed as a country that welcomes foreigners and protects gamblers but is, at the same time, stubbornly incapable of adapting to modernity and globalization.

In a partly deleted scene, Gusteau, forced to market frozen food, complains about the fact his "foie gras pockets" don't sell. When Skinner then 
recommends microwave burritos, he retorts: "I hate microwave burritos ... [They] are not Gusteau. They are not even French!" Skinner proposes "corn dog puppies," presented as "cheap sausages dipped in butter and deep fried. You know, American," adding, in order to convince his boss: "Well, we wouldn't actually call them 'corn dog puppies.' We make it appear gourmet. Better meat, change the shape, give it a pretentious name and charge triple." Gusteau, in despair, then asks, "What has happened to us, Skinner?" And Skinner replies, "We woke up." But this kind of unwanted awakening will not last: When Linguini is declared the heir to the restaurant, the team makes a bonfire of all the advertisements for frozen food, an ambiguous gesture that can be interpreted as an anti-American statement concerning frozen fast food or as a critique of the French's inability to democratize goods reserved for an elite.

According to Ratatouille, France never woke up, reflecting both its charm and its limitations. Paris, the home of this queer cuisine experiment, is a city that ignores modernity. "In Paris, nothing feels new," declares Sharon Calahan, the director of photography. This "feeling," shared by the movie director, corresponds to the portrayed image of the city. Recent monuments such as the Tour Montparnasse, La Défense, or the Centre Pompidou have been erased from the picture. The timeframe has been manipulated so that it becomes impossible to date the plot. Television sets, mopeds, buses, and cars (the famous Citroën DS or 2CV), distinctive of the I950s or I960s look similar, but license-plates bear the European sticker created in 1992. Colette also rides a state-of-the-art motorcycle.

The aforementioned ideological equation between Ratatouille, French universalism, and "the melting pot," which contradicts the emerging queerness of Remy, is then layered with the ambiguity produced by the rendition of Paris as a sort of hodgepodge of objects whose historical provenance jumbles time periods while accessing a familiar French anti-Americanism. This weird time warp creates a feeling of a timeless city of romance that matches Remy's ideal of the sacred capital of gastronomy: The capital is too perfect to be true, just as the final ratatouille in the movie is a clean version of the original "bad stew." This cliché is not only an American bias, inherited from hundreds of photographs and films, from An American in Paris (195 I) and The Aristocats (1970) to French Kiss (1995). I would argue that it is also an image that France sometimes likes to give of itself, in films such as Le Fabuleux destin d'Amélie Poulain (2001). ${ }^{6}$

As Ratatouille well exemplifies, France is stuck in an uncomfortable position. Its heritage - food, fashion, historical architecture, and way of lifeattracts 45 million tourists every year but at the same time also curbs the 
expansion of the city, which has not changed its boundaries since $\mathrm{I} 860$ and is in danger of being transformed into a huge outdoor museum.

French cuisine does not escape this pattern. On February 23, 2008, at the Salon de l'Agriculture in Paris, the French president Nicolas Sarkozy proposed to list French gastronomy as part of the Unesco World Intangible Heritage (in French, it sounds a bit different, "intangible" being translated into "immatériel," which is not the first image that comes to mind when we talk about cuisine). He declared: "We have the best gastronomy in the world," adding, without the slightest irony, "well, from our point of view." The question that would probably be worth addressing is whether the old provençale murky ratatouille is truly compatible with the ministry of "identité française."

\section{Coda}

On March 5, 2009, I was to give a lecture on Ratatouille and queer theory at UCLA. An announcement for this lecture was posted on the site of the French Embassy, but with the wrong title and using an old abstract circulating on the net, summarizing a 20-minute lecture that I had given on the same topic for the conference "Rhetoric of the Other" held at the University of Urbana-Champagne (Illinois) in March 2008. In this abstract, I had stated that Ratatouille "could also be read as the story of a coming-out-not out of the closet but out of the chef's hat-where Remy embodies the symbolic lonely gay" (my emphasis). This piece of information was taken up on a blog of the L.A. Times, where the lecture was presented, more directly, as a demonstration of Ratatouille being "the story of a homosexual comingout" (Hallock 2009). Within two days, the allegorical became real, and Remy a drag queen.

In less than 24 hours, not only was the information published in USA Today, but hundreds of scandalous comments from all over the world were published on the web: "Ridiculous," "outrageous," "the professor is over reaching" were among the nicest comments, while the "gay lobby" was associated with "pedophilia" and French people, as usual, were portrayed as obsessed and corrupted by "theory." Some asked that the UCLA French Department close and be replaced by the English Department-which was a risky proposition, considering the native language and country of origin of queer theory. The most perceptive blogger noticed that there was the word "rat" in "Murat," a point that I willingly concede. Needless to say: Nobody had read or heard, even could have read or heard, the lecture that had not yet been delivered, and had never been published. 
What this anecdote teaches us, besides confirming the frightening power of the web and the disproportionate consequences of a tiny series of posted errors and editorial shortcuts, is that applying queer theory as a metonymic method and using it as a tool of analysis remains widely misunderstood. First, the meaning of "queer" is still limited to "gay," spuriously othered to the "French" and disturbingly connected to pedophilia, and not assimilated as a word designating people who are escaping the traditional boundaries of sex, race, and gender or heteronormative society, regardless of their sexuality. Second, and more disturbing, gay/queer thought applied to children's entertainment still remains associated with a threat, a shocking moral "abuse," and a kind of hijacking of movies that are, as a blogger said, "only cute."

Comic strips, cartoons, animated movies are a great observatory to understand what kind of a world is proposed to today's children. I suppose bloggers would agree that an open world, with different approaches and diverse ways of living, is preferable to a univocal civilization. 